\title{
Brugada syndrome: a review of the literature
}

\author{
Authors: Azeem S Sheikh ${ }^{A}$ and Kula Ranjan ${ }^{B}$
}

\begin{abstract}
Brugada syndrome is an example of a channelopathy caused by an alteration in the transmembrane ion currents that together constitute the cardiac action potential. Approximately $20 \%$ of the cases of Brugada syndrome have been shown to be associated with mutations in the gene coding for the sodium ion channel in the cell membranes of the muscle cells of the heart. Patients with Brugada syndrome are prone to develop ventricular tachyarrhythmias that may lead to syncope, cardiac arrest or sudden cardiac death. Many clinical situations have been reported to unmask or exacerbate the electrocardiography (ECG) pattern of Brugada syndrome. Genetic testing for Brugada syndrome is clinically available. Here we report two cases of Brugada syndrome followed by a comprehensive review of the literature.
\end{abstract}

KEYWORDS: Brugada syndrome, atrial fibrillation, sudden cardiac death, syncope, channelopathy

\section{Introduction}

Brugada syndrome (BS), first described in $1992,{ }^{1}$ is a major cause of sudden cardiac death (SCD), ${ }^{2}$ syncope and ventricular tachyarrhythmia in young people with no structural heart disease. ${ }^{1}$ About $5 \%$ of survivors of cardiac arrest have no clinically identified cardiac abnormality. About half of such cases are thought to be due to $\mathrm{BS}^{3}$

The syndrome should be suspected in patients with documented idiopathic ventricular fibrillation, self-terminating polymorphic ventricular tachycardia, a family history of sudden cardiac death in a young person and/or syncope with the characteristic electrocardiography (ECG) changes. BS is usually diagnosed in adulthood, with an incidence of $0.05-0.60 \%$ in adults, and is very rarely diagnosed in children; the average patient age at diagnosis was 41 years in two large studies. ${ }^{5}$ The Brugada pattern is much more common in men with a ratio of 9:1 in one study; ${ }^{6}$ men had a higher rate of syncope and sudden cardiac death in a large prospective registry study. ${ }^{7}$ The syndrome characterised by right bundle branch block (RBBB) with ST elevation in leads V1 to V3 on electrocardiogram can transiently normalise for a period of time, making it difficult to diagnose. ${ }^{8}$

Authors: ${ }^{\text {A }}$ specialist registrar in cardiology, Royal Glamorgan Hospital, Ynysmaerdy, Llantrisant, Pontyclun, UK; B consultant cardiologist, Newham University Hospital NHS Trust, London, UK
We report two cases here, one presenting with atrial fibrillation who developed ventricular fibrillation after being treated with flecainide, unmasking the Brugada ECG pattern, and the other admitted with a history of collapse. These cases are followed by a comprehensive review of the published literature.

\section{Case 1}

A 25-year-old man was admitted to the accident and emergency (A\&E) department with a history of collapse. There was no significant previous history. His blood pressure was $129 / 65 \mathrm{mmHg}$ and pulse was 160 beats per minute. Otherwise, examination was unremarkable.

An ECG showed atrial fibrillation (Fig 1a). Metoprolol 5 mg intravenous (IV) bolus had no effect. He was then given flecainide $150 \mathrm{mg}$ over 30 minutes, but after 20 minutes of flecainide loading he became very pale and developed ventricular tachycardia leading to ventricular fibrillation (Fig 1b). One shock of $360 \mathrm{~J}$ resulted in return of spontaneous circulation (ROSC) and reversion to sinus rhythm. His repeat ECG showed RBBB with ST elevation in V1 to V2, suggesting Brugada syndrome Type 1 (Fig 1c). A repeat ECG after 3 hours proved to be normal without any feature of Brugada-type ECG pattern (Fig 1d).

\section{Case 2}

A 57-year-old male collapsed and lost consciousness while sitting at home. His ECG showed RBBB with ST elevation in V1-V3 (Fig 2). His investigations showed a haemoglobin level of $13.7 \mathrm{~g} / \mathrm{dl}$, white cell count $12 \times 10^{9} / \mathrm{l}$, C-reactive protein $35 \mathrm{mg} / \mathrm{l}$, sodium $137 \mathrm{mmol} / \mathrm{l}$, potassium $4.3 \mathrm{mmol} / \mathrm{l}$, creatinine $141 \mu \mathrm{g} / \mathrm{l}$ and urea $7.2 \mathrm{mmol} / \mathrm{l}$. His chest X-ray (CXR) revealed consolidation of the right base and he was treated for chest infection with antibiotics. His transthoracic echocardiogram revealed good left ventricular systolic function with no evidence of structural heart disease. He was referred to an electrophysiologist for further management.

\section{Discussion \\ Background}

Brugada syndrome (BS) is an example of a channelopathy: a disease caused by an alteration in the transmembrane ion currents that together constitute the cardiac action potential. BS is consistent with an autosomal dominant inheritance with a variable expression. 


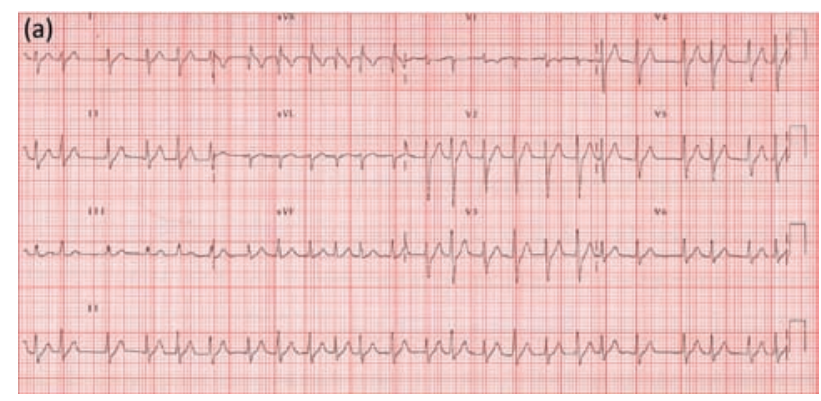

(b)
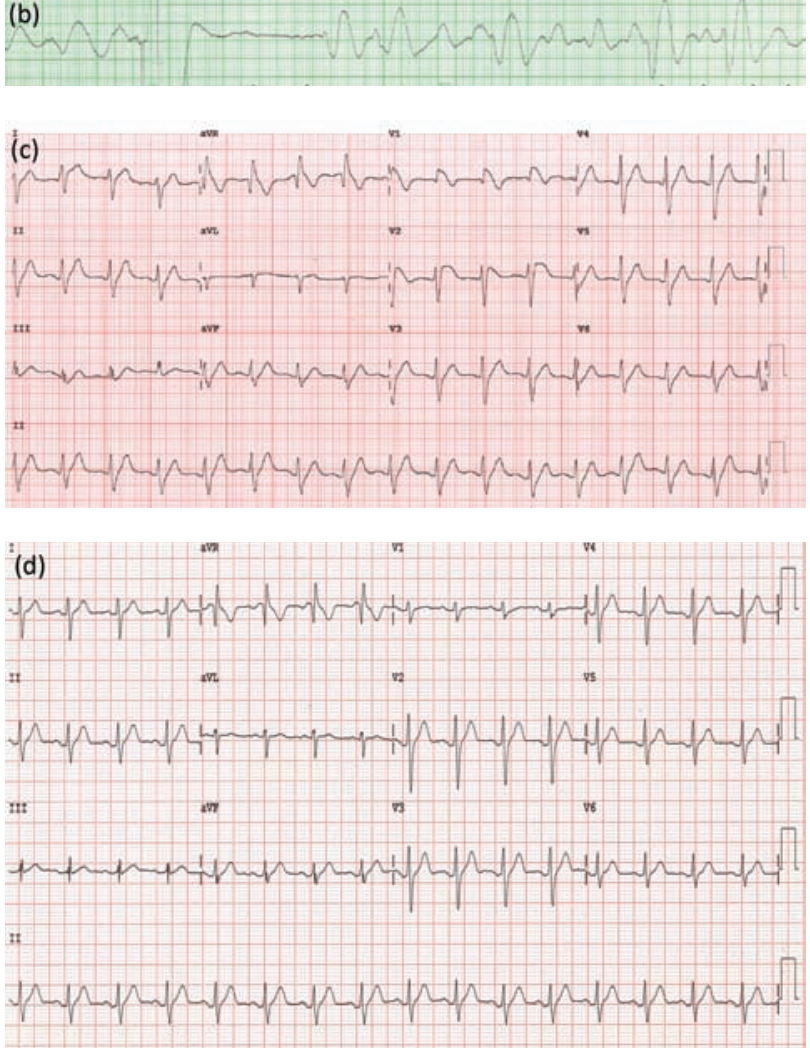

Fig 1. (a) The 12-lead ECG on admission showing atrial fibrillation with fast ventricular rate. (b) The rhythm strip from the monitor showing ventricular fibrillation post flecainide loading. (c) The 12-lead ECG after the shock showing ST right bundle branch block with ST elevation in V1-V2, suggestive of Brugada syndrome type 1.

(d) Repeat 12-lead ECG 3 hours later showing no feature suggestive of Brugada syndrome. $E C G$ = electrocardiography.

Several mutations have been identified in genes encoding subunits of cardiac sodium, potassium and calcium channels, as well as in genes involved in the trafficking or regulation of these channels. Accordingly, eight types of BS (from BS1 to BS8) have already been described, involving mutations in the SCN $5 A,{ }^{9}$ GPD $1-L,{ }^{10}$ CACNA $1 C,{ }^{11}$ CACNB2,${ }^{11}$ SCN $1 B,{ }^{12}$ KCNE $3,{ }^{13} S C N 3 B^{14}$ and $H C N 44^{15}$ genes. The prototypical case of $\mathrm{BS}$ has been associated with alterations in the sodium channel gene SCN5A, of which nearly 300 mutations have been described. ${ }^{16}$ Mutations in this gene, located on chromosome 3p21-24, have been found in $18-30 \%$ of families. ${ }^{2,5,9}$

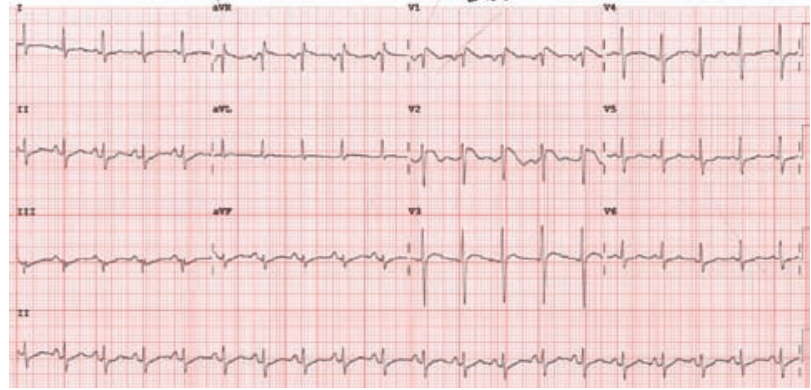

Fig 2. The 12-lead ECG showing Brugada ECG pattern.

ECG $=$ electrocardiography.

Standard cardiac testing, including echocardiography, stress testing and cardiac magnetic resonance imaging (MRI), often reveals no structural abnormalities. BS may be categorised as a disorder that occurs in hearts that are apparently normal, as some evidence suggests that there may be subtle structural or microscopic abnormalities, including dilation of the right ventricular outflow tract (RVOT) and localised inflammation and fibrosis. ${ }^{17,18}$

\section{Clinical presentation}

Sudden cardiac arrest (SCA) may be the first and only clinical event in BS, occurring in up to one-third of patients with BS. Arrhythmic events are more common at night and during sleep; ${ }^{19}$ SCA in patients with BS is usually not related to exercise. ${ }^{20}$

The most significant clinical manifestations of BS are ventricular arrhythmias, although these patients may also be at risk of atrial arrhythmias, most notably atrial fibrillation $(\mathrm{AF}),{ }^{21,22}$ as seen in Case 1 . The incidence of AF is higher in BS patients than in control subjects ${ }^{22}$ and the presence of AF has been associated with increased disease severity and a higher risk of ventricular fibrillation $(\mathrm{VF}) .^{21}$

Over a 3-year follow up in 59 patients with BS and 31 matched control subjects, AF occurred in $12(20 \%)$ of the BS patients but none of the control subjects. Patients with AF had a higher incidence of syncope ( $60 \%$ vs $22 \%$ of patients without AF), and VF $(40 \%$ vs $14 \%) .^{21}$

Characteristic BS patterns on an electrocardiogram may be present at all times or may be elicited by the administration of particular drugs. Many events unmask or exacerbate the ECG pattern of BS. Examples include: febrile state, hyperkalaemia, hypokalaemia, hypercalcaemia, alcohol or cocaine intoxication, and the use of certain medications, including sodium channel blockers, vagotonic agents, $\alpha$-adrenergic agonists, $\beta$-adrenergic blockers, heterocyclic antidepressants and a combination of glucose and insulin. ${ }^{23}$

\section{Diagnosis and types}

Brugada syndrome is diagnosed in patients with typical ECG findings (coved ST elevation in leads V1-V3) plus at least one additional criterion from: a personal or family history of syncope, ventricular arrhythmias, or similar ECG findings in other family members. ${ }^{24}$ The 


\section{A. Type 1: coved pattern}

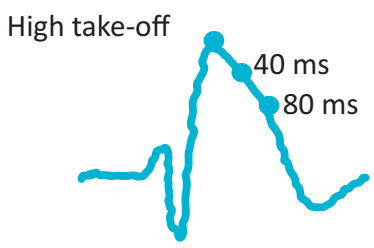

This typical coved pattern present in $\mathrm{V} 1-\mathrm{V} 2$ shows the following:

1 At the end of QRS, an ascending and quick slope with a high take-off $\geq 2 \mathrm{~mm}$ followed by concave or rectilinear down sloping ST. There are few cases of coved pattern with a high take-off between 1 and $2 \mathrm{~mm}$.

2 There is no clear $r^{\prime}$ wave.

3 The high take-off often does not correspond with the J point.

4 At $40 \mathrm{~ms}$ of high take-off, the decrease in amplitude of ST is $\leq 4 \mathrm{~mm}$. In RBBB and athletes, it is much higher.

5 ST at high take-off $>$ ST at $40 \mathrm{~ms}>$ ST at $80 \mathrm{~ms}$.

6 ST is followed by negative and symmetric T wave.

7 The duration of QRS is longer than in RBBB, and there is a mismatch between V1 and V6.
B. Type 2: saddle-back pattern

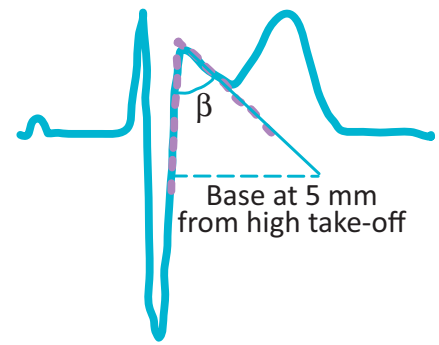

This typical saddle-back pattern present in V1-V2 shows the following:

1 High take-off of $r^{\prime}$ (that often does not coincide with J point) $\geq 2 \mathrm{~mm}$.

2 Descending arm of $r^{\prime}$ coincides with beginning of ST (often is not well seen).

3 Minimum ST ascent $\geq 0.5 \mathrm{~mm}$.

4 ST is followed by positive T wave in V2 (T peak > ST minimum $>0$ ) and of variable morphology in $\mathrm{V} 1$.

5 The characteristics of triangle formed by $r^{\prime}$ allow to define different criteria useful for diagnosis.

- $\beta$ angle.

- Duration of the base of the triangle of $r^{\prime}$ at $5 \mathrm{~mm}$ from the high take-off greater than $3.5 \mathrm{~mm}$.

6 The duration of QRS is longer in Brugada pattern type 2 than in other cases with $r^{\prime}$ in $\mathrm{V} 1$, and there is a mismatch between $\mathrm{V} 1$ and $\mathrm{V} 6$.

Fig 3. ECG patterns of Brugada syndrome in leads V1-V2. Reproduced with permission from Bayés de Luna et al (2012). ${ }^{25}$ ECG = electrocardiography.

typical ECG changes alone are considered to represent an idiopathic Brugada ECG - ie the pattern is present, but BS is not. ${ }^{2,24}$ Both ECG and clinical features are important in establishing the diagnosis., 24

Two different patterns of ST elevation have been described (Fig 3). ${ }^{25}$

> In the classic Brugada Type 1 ECG, the elevated ST segment ( $\geq 2 \mathrm{~mm}$ ) descends with an upward convexity to an inverted T wave. This is referred to as the 'coved type' Brugada pattern.

$>$ In the Type 2 pattern (combined from the original designation of types 2 and 3 patterns, Table 1$),{ }^{26}$ the ST segment is $\geq 2 \mathrm{~mm}$ elevated and has a 'saddle back' ST-T wave configuration, in which the elevated ST segment descends toward the baseline but remains at least $0.5 \mathrm{~mm}$ above the isoelectric baseline, and then rises again to an upright or biphasic $\mathrm{T}$ wave.

\section{Diagnostic criteria}

In view of the clinical variability in presentation and the different ECG manifestations which can be seen in patients with Brugada syndrome, diagnostic criteria have been proposed by professional societies from both Europe and North America. ${ }^{2,24}$

\section{Type 1}

The HRS/EHRA/APHRS expert consensus statement ${ }^{27}$ recommends that Brugada syndrome is diagnosed when a Type 1 ST-segment elevation (coved type; Fig 3 ) is observed either spontaneously or after intravenous administration of a sodium channel blocking agent in at least one right precordial lead (V1 and V2), ${ }^{28}$ which are placed in a standard or a superior position (up to the second intercostal space). ${ }^{29,30}$

\section{Type 2}

The second consensus report ${ }^{2}$ proposed that the diagnosis should be strongly considered in patients with a Type 2 Brugada ECG showing Type 2 ST-segment elevation (saddle-back type; Fig 3) in more than one right precordial lead under baseline conditions, with conversion to Type 1 following challenge with a sodium channel blocker, plus at least one of the following:

$>$ documented ventricular fibrillation

$>$ polymorphic ventricular tachycardia (VT)

$>$ family history of sudden cardiac death at less than 45 years of age

> family history of Type 1 Brugada pattern ECG changes

$>$ inducible VT during electrophysiology study

$>$ unexplained syncope suggestive of a tachyarrhythmia

$>$ nocturnal agonal respiration. 


\section{Key points}

> Brugada syndrome, an autosomal dominant condition, is a disorder characterised by sudden death associated with one of several ECG patterns characterised by incomplete right bundle-branch block and ST-segment elevations in the anterior precordial leads.

> Patients with Brugada syndrome are prone to develop ventricular tachyarrhythmias that may lead to syncope, cardiac arrest, or sudden cardiac death.

> Diagnosis is based on clinical findings. Mutations in eight genes (SCN5A, GPD1L, CACNA1C, CACNB2, SCN1B, KCNE3, SCN3B, and HCN4) are known to cause Brugada syndrome.

$>$ At present, implantation of an automatic implantable cardiac defibrillator (ICD) is the only treatment proven effective in treating ventricular tachycardia and fibrillation and preventing sudden death in patients with Brugada syndrome.

$>$ No proven pharmacologic treatment for preventing SCD in BS have been found, although Isoproterenol has been proved to be useful for treatment of electrical storm in BS and Quinidine has also shown to be beneficial. Quinidine is currently being used in:

- patients with ICD and multiple shocks;

- cases in which ICD implantation is contraindicated; or

- for the treatment of supraventricular arrhythmias.

\section{Differential diagnosis}

The differential diagnosis for Brugada pattern ECG changes includes other conditions that result in apparent conduction and ST segment abnormalities in leads V1 to V3 on the ECG. A list of such conditions are shown in Box 1.

\section{Box 1. Differential diagnosis of Brugada} pattern ECG.

\author{
$>$ Atypical right bundle branch block \\ > Arrhythmogenic right ventricular cardiomyopathy (ARVC) \\ $>$ Early repolarisation \\ $>$ Acute pericarditis \\ $>$ Acute myocardial ischaemia or infarction \\ $>$ Pulmonary embolism \\ $>$ Dissecting aortic aneurysm \\ $>$ Hyperkalaemia \\ $>$ Hypercalcaemia \\ $>$ Hypothermia \\ $>$ Pectus excavatum
}

$\mathrm{ECG}=$ electrocardiography.

The Brugada pattern on ECG can be seen as an early subclinical manifestation of arrhythmogenic right ventricular cardiomyopathy (ARVC) ${ }^{8}$ An association between ARVC and the Brugada pattern on ECG is suggested by a report of 96 victims of sudden cardiac death (SCD) who were aged $\leq 35$ years and had a baseline ECG available. ${ }^{20}$ Right precordial ST segment elevation with or without RBBB was present in 13 (14\%) of these; at autopsy, all but one had ARVC.

In patients with clinical manifestations of ventricular tachyarrhythmias and no apparent cardiac structural abnormalities, a number of other conditions should be considered along with:

> congenital long QT syndrome (LQTS)

$>$ acquired LQTS with polymorphic ventricular tachycardia (VT)

Table 1. Diagnostic criteria for Brugada syndrome. ST segment abnormalities in leads V1-V3. $1 \mathrm{~mm}=0.1 \mathrm{mV}$; the terminal portion of the ST segment refers to the latter half of the ST segment.

Type 1

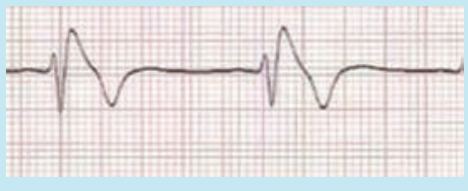

J wave

amplitude

T wave

ST-T

configuration

Terminal part of ST segment

$\geq 2 \mathrm{~mm}$

Negative

Coved type

Gradually descending
Type 2

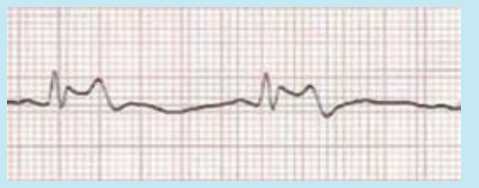

$\geq 2 \mathrm{~mm}$

Positive or biphasic

Saddle-back type

Elevated $\geq 1 \mathrm{~mm}$
Type 3

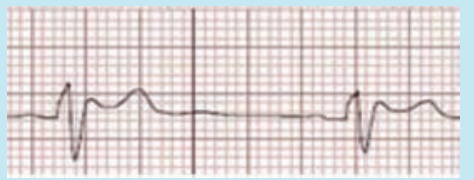

$\geq 2 \mathrm{~mm}$

Positive

Saddle-back type

Elevated $<1 \mathrm{~mm}$

Reproduced with permission from Wilde et al (2002). ${ }^{26}$ 
Table 2. Sodium channel blocking agents used to unmask Brugada syndrome.

\begin{tabular}{|c|c|c|c|c|}
\hline Drug & Anti-arrhythmic class & Dosage & $\begin{array}{l}\text { Route of } \\
\text { administration }\end{array}$ & $\begin{array}{l}\text { Duration of } \\
\text { administration }\end{array}$ \\
\hline Ajmaline $^{28}$ & $1 \mathrm{~A}$ & $1 \mathrm{mg} / \mathrm{kg}$ & IV & $10 \mathrm{~min}$ \\
\hline Flecainde 28 & $1 C$ & $2 \mathrm{mg} / \mathrm{kg}$ & IV & $10 \mathrm{~min}$ \\
\hline Flecainide $^{28}$ & $1 C$ & $400 \mathrm{mg}$ & Oral & Stat dose \\
\hline Procainamide 29,30 & $1 \mathrm{~A}$ & $10 \mathrm{mg} / \mathrm{kg}$ & IV & $10 \mathrm{~min}$ \\
\hline Pilsicainide $e^{31}$ & $1 C$ & $1 \mathrm{mg} / \mathrm{kg}$ & IV & $10 \mathrm{~min}$ \\
\hline
\end{tabular}

> catecholaminergic polymorphic VT

$>$ idiopathic VT

$>$ idiopathic ventricular fibrillation

$>$ short QT syndrome

$>$ commotio cordis.

Analysis of the ST-T waveform usually permits differential diagnosis between a Brugada ECG and right precordial early repolarisation seen in athlete's heart. Athletes exhibit an upsloping $\mathrm{ST}$-segment with a mean $\mathrm{ST}_{\mathrm{j}}: \mathrm{ST}_{80}$ ratio of $\leq 1$, whereas Brugada patients show a downsloping ST-segment with a $\mathrm{ST}_{\mathrm{j}}: \mathrm{ST}_{80}$ ratio of $>1 .^{31}$ The athlete with a suspected Brugada ECG should be referred to a cardiologist/electrophysiologist for further clinical work up, including a pharmacological test with sodium channel blocking, risk stratification and familial evaluation.

For most conditions in which VT or SCD occurs with no apparent cardiac structural abnormalities, the clinical scenario and the ECG findings can be used to exclude other conditions. For example:

> Patients with VT or SCD associated with prolongation of the QT interval are more likely to have LQTS than Brugada syndrome, particularly if the patient has been exposed to medications which may prolong the QT interval. Similarly, patients with VT or SCD whose QT interval is markedly shortened are more likely to have short QT syndrome.

> Patients who experience VT or SCD in the setting of exertion are more likely to have catecholaminergic polymorphic VT than Brugada syndrome, in which symptomatic tachyarrhythmias are more likely to occur at rest.

> Patients with VT or SCD following blunt chest trauma are more likely to have experienced commotio cord.

Among patients with the Brugada Type 2 ECG pattern, the Brugada Type 1 ECG pattern can occasionally be unmasked by sodium channel blockers (eg flecainide, procainamide, ajmaline and pilsicainide) (Table 2). ${ }^{2,32}$ The reported sensitivity of pharmacologic challenge with these drugs range between $100 \%{ }^{32}$ to as low as $15 \%$. $^{33}$

\section{Electrophysiology studies}

The role of electrophysiology (EP) testing in patients with known or suspected BS depends largely upon the presence or absence of associated symptoms. Patients with a Brugada ECG pattern and certain high-risk clinical features (ie history of SCA and/or sustained ventricular arrhythmias) are known to have an increased risk of SCD. ${ }^{3,8,19}$ In asymptomatic patients, EP testing remains debatable. ${ }^{34}$

In the PRogrammed ELectrical stimUlation preDictive valuE (PRELUDE) trial, Priori and colleagues enrolled 308 patients with no history of cardiac arrest but with a spontaneous or drug-induced Type I Brugada ECG pattern. ${ }^{35}$ Seventy-eight of these patients had an implantable cardiac defibrillator (ICD) implanted prophylactically. An EP study with a consistent stimulation protocol was performed.

Over a mean follow up of 34 months no differences were found in the incidence of appropriate ICD shocks or cardiac arrest between patients who had or did not have inducible arrhythmias during the EP study.

\section{Management}

No proven pharmacologic treatment for preventing SCD in BS have been found, although isoproterenol has been proved to be useful for treatment of electrical storm in $\mathrm{BS}^{36}$ and quinidine has also shown to be beneficial. ${ }^{37}$

Among 25 patients (15 symptomatic and 10 asymptomatic) before and after treatment with quinidine bisulfate (mean dose $1483 \pm 240 \mathrm{mg} /$ day), ${ }^{37}$ ventricular fibrillation was inducible in all patients at baseline electrophysiology testing, but in only three after a few days of quinidine therapy. Quinidine treatment was continued in 19 patients for a mean of 56 months and none had arrhythmic events. Quinidine is currently being used in patients with ICD and multiple shocks, cases in which ICD implantation is contraindicated or for the treatment of supraventricular arrhythmias. ${ }^{38}$ A list of potential antiarrhythmic drugs for the treatment of patients with BS are given in Table 3.

Table 3. Potential antiarrhythmic drugs in patients with Brugada syndrome.

\begin{tabular}{lll}
$\begin{array}{lll}\text { Drug category } \\
\text { Anti-arrhythmic } \\
\text { drugs }\end{array}$ & $\begin{array}{l}\text { Drug (generic) } \\
\text { Isoproterenol/ } \\
\text { isoprenaline }\end{array}$ & $\begin{array}{l}\text { Recommendation* } \\
\text { Class I }\end{array}$ \\
& $\begin{array}{l}\text { Orciprenaline } \\
\text { Quinidine }\end{array}$ & Class IIa \\
& Class I \\
Other substances & Cilostazol & Class IIb \\
\hline
\end{tabular}

Reproduced with permission from Postema et al (2009). ${ }^{39}{ }^{*}$ Class I: convincing evidence/opinion; class IIa: evidence/opinion less clear; class IIb: conflicting evidence/opinion. 
Table 4. Drugs to be avoided in patients with Brugada syndrome.

\begin{tabular}{lll} 
Drug category & Drug (generic) & Recommendation* \\
Anti-arrhythmic drugs & Ajmaline & Class I \\
& Flecainide & Class I \\
& Pilsicainide & Class I \\
& Procainamide & Class I \\
& Propafenone & Class IIa \\
Psychotropic drugs & Amytriptyline & Class IIa \\
& Clomipramine & Class IIa \\
& Desipramine & Class IIa \\
& Lithium & Class IIb \\
& Loxapine & Class IIa \\
& Nortriptyline & Class IIa \\
Anaesthetic drugs & Bupivicaine & Class IIa \\
& Procaine & Class IIa \\
& Propofol & Class IIa \\
Other substances & Acetylcholine & Class IIa \\
& Alcohol (toxicity) & Class IIb \\
\hline evidence/opinion; class IIa: evidence/opinion less clear; class IIb: conflicting \\
& Cocaine & Class IIa \\
& Ergonovine & Class IIb \\
\hline evinion. & &
\end{tabular}

Some drugs have been reported to induce the Type 1 BS ECG pattern and/or (fatal) arrhythmias in BS patients. Patients with BS can prevent arrhythmias by avoiding these drugs (Table 4 and Table 5$)^{39}$ or by using them only in controlled conditions. ${ }^{10}$

The only treatment with proven efficacy in preventing SCD is an ICD. In a cohort of 63 patients, both amiodarone and $\beta$-blockers were found to be inferior to ICD. ${ }^{40}$ Selecting patients for an ICD is challenging. The proposed recommendations of ICD in patients with BS are shown in Fig $4 .^{27}$

Asymptomatic BS patients do not qualify for an ICD as their risk for life-threatening events is very low. ${ }^{41}$ Patients in this group need to be assessed individually based on their gender, age, baseline ECG and inducibility.

\section{References}

1 Brugada P, Brugada J. Right bundle branch block, persistent ST segment elevation and sudden cardiac death: a distinct clinical and electrocardiographic syndrome. A multicenter report. J Am Coll Cardiol 1992;20:1391-6.

2 Antzelevitch C, Brugada P, Borggrefe $\mathrm{M}$ et al. Brugada syndrome: report of the second consensus conference: endorsed by the Heart Rhythm Society and the European Heart Rhythm Association. Circulation 2005;111:659-70

3 Alings M, Wilde A. 'Brugada' syndrome: clinical data and suggested pathophysiological mechanism. Circulation 1999;99:666-73.

4 Tohyou Y, Nakazawa K, Ozawa A et al. A survey in the incidence of right bundle branch block with ST segment elevation among normal population. Jpn J Electrocardiology 1995;15:223-6.
Table 5. Drugs preferably avoided in patients with Brugada syndrome.

\begin{tabular}{|c|c|c|}
\hline Drug category & Drug (generic) & Recommendation* \\
\hline \multirow[t]{6}{*}{ Anti-arrhythmic drugs } & Amiodarone & Class IIb \\
\hline & Cibenzoline & Class IIb \\
\hline & Disopyramide & Class IIb \\
\hline & $\begin{array}{l}\text { Lidocaine } \\
\text { (lignocaine) }\end{array}$ & Class IIb \\
\hline & Propranolol & Class IIb \\
\hline & Verapamil & Class IIb \\
\hline \multirow[t]{9}{*}{ Psychotropic drugs } & Carbamazepine & Class IIb \\
\hline & Cyamemazine & Class IIb \\
\hline & Doxepin & Class IIb \\
\hline & Fluoxetine & Class IIb \\
\hline & Imipramine & Class IIb \\
\hline & Maprotiline & Class IIb \\
\hline & Perphenazine & Class IIb \\
\hline & Phenytoin & Class IIb \\
\hline & Thioridazine & Class IIb \\
\hline \multirow[t]{5}{*}{ Anti-anginal drugs } & Diltiazem & Class III \\
\hline & Nicorandil & Class III \\
\hline & Nifedipine & Class III \\
\hline & Nitroglycerine & Class III \\
\hline & Sorbidnitrate & Class III \\
\hline \multirow[t]{3}{*}{ Other substances } & Dimenhydrinate & Class IIb \\
\hline & Edrophonium & Class IIb \\
\hline & Indapamide & Class IIb \\
\hline
\end{tabular}

Reproduced with permission from Postema et al (2009). ${ }^{39}$ *Class I: convincing evidence/opinion; class IIa: evidence/opinion less clear; class IIb: conflicting evidence/opinion; class III: very little evidence.

5 Priori SG, Napolitano C, Gasparini M et al. Natural history of Brugada syndrome: insights for risk stratification and management. Circulation 2002;105:1342-7.

6 Matsuo K, Akahoshi M, Nakashima E et al. The prevalence, incidence and prognostic value of the Brugada-type electrocardiogram: a population-based study of four decades. J Am Coll Cardiol 2001;38:765-70.

7 Benito B, Sarkozy A, Mont L et al. Gender differences in clinical manifestations of Brugada syndrome. J Am Coll Cardiol 2008;52:1567-73.

8 Gussak I, Antzelevitch C, Bjerregaard P et al. The Brugada syndrome: clinical, electrophysiologic and genetic aspects. J Am Coll Cardiol 1999;33:5-15.

9 Chen Q, Kirsch GE, Zhang D et al. Genetic basis and molecular mechanisms for idiopathic ventricular fibrillation. Nature 1998;392:293-6.

10 London B, Michalec M, Mehdi $\mathrm{H}$ et al. Mutation in glycerol3-phosphate dehydrogenase 1-like gene (GPD1-L) decreases cardiac $\mathrm{Na}^{+}$current and causes inherited arrhythmias. Circulation 2007;116:2260-8.

11 Antzelevitch C, Pollevick GD, Cordeiro JM et al. Loss-of-function mutations in the cardiac calcium channel underlie a new clinical entity characterized by ST-segment elevation, short QT intervals, and sudden cardiac death. Circulation 2007;115:442-49. 

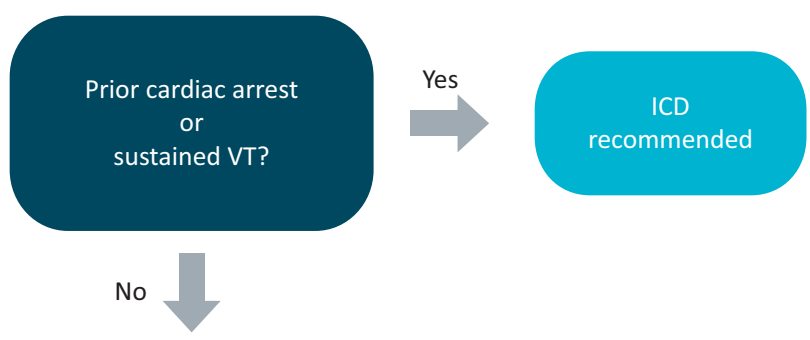

Spontaneous Type I ECG and history of syncope judged to be caused by ventricular arrhythmias?
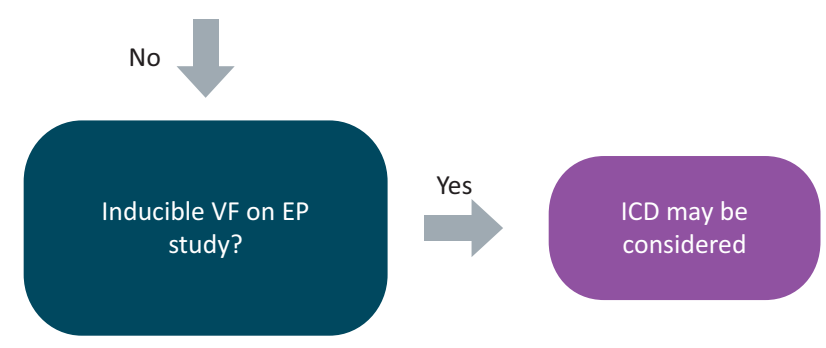

No or no EP study
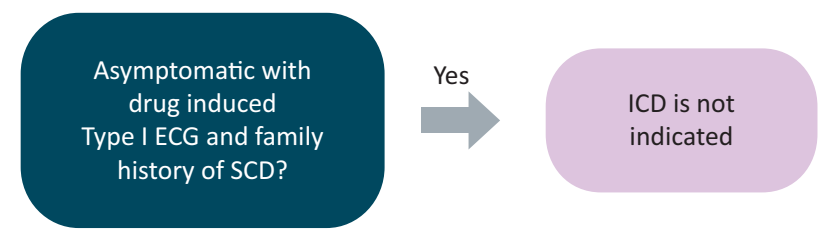

Fig 4. Consensus recommendations for implantable cardiac defibrillators (ICDs) in patients diagnosed with Brugada syndrome. Reproduced with permission from Priori et al (2013). ${ }^{27} \mathrm{ECG}=$ electrocardiography; EP = electrophysiology; $\mathrm{ICD}=$ implantable cardiac defibrillator; $\mathrm{SCD}=$ sudden cardiac death; $\mathrm{VT}=$ ventricular tachycardia.

12 Watanabe H, Koopmann TT, Le Scouarnec S et al. Sodium channel $\beta 1$ subunit mutations associated with Brugada syndrome and cardiac conduction disease in humans. J Clin Invest 2008;118:2260-8.

13 Delpón E, Cordeiro JM, Núñez L et al. Functional effects of KCNE3 mutation and its role in the development of brugada syndrome. Circ Arrhythm Electrophysiol 2008;1:209-18.

$14 \mathrm{Hu}$ D, Barajas-Martinez H, Burashnikov E et al. A mutation in the $\beta 3$ subunit of the cardiac sodium channel associated with Brugada ECG phenotype. Circ Cardiovasc Genet 2009;2:270-8.

15 Ueda K, Hirano Y, Higashiuesato Y et al. Role of HCN4 channel in preventing ventricular arrhythmia. J Hum Genet 2009;54:115-21.

16 Kapplinger JD, Tester DJ, Alders $\mathrm{M}$ et al. An international compendium of mutations in the SCN5A-encoded cardiac sodium channel in patients referred for Brugada syndrome genetic testing. Heart Rhythm 2010;7:33-46.

17 Frustaci A, Priori SG, Pieroni M et al. Cardiac histological substrate in patients with clinical phenotype of Brugada syndrome. Circulation 2005;112:3680.

18 van Veen TA, Stein M, Royer A et al. Impaired impulse propagation in Scn5a-knockout mice: combined contribution of excitability, connexin expression, and tissue architecture in relation to aging. Circulation 2005;112:1927-35.
19 Atarashi H, Ogawa S, Harumi K et al. Characteristics of patients with right bundle branch block and ST-segment elevation in right precordial leads. Idiopathic Ventricular Fibrillation Investigators. Am J Cardiol 1996;78:581-3.

20 Corrado D, Basso C, Buja G et al. Right bundle branch block, right precordial ST-segment elevation, and sudden death in young people. Circulation 2001;103:710-7.

21 Kusano KF, Taniyama M, Nakamura K et al. Atrial fibrillation in patients with Brugada syndrome relationships of gene mutation, electrophysiology, and clinical backgrounds. J Am Coll Cardiol 2008;51:1169-75.

22 Bordachar P, Reuter S, Garrigue S et al. Incidence, clinical implications and prognosis of atrial arrhythmias in Brugada syndrome. Eur Heart J 2004;25:879-84.

23 Antzelevitch C, Brugada P, Brugada J, Brugada R. Brugada syndrome: from cell to bedside. Curr Probl Cardiol 2005;30:9-54.

24 Wilde AA, Antzelevitch C, Borggrefe M et al; Study Group on the Molecular Basis of Arrhythmias of the European Society of Cardiology. Proposed diagnostic criteria for the Brugada syndrome. Eur Heart J 2002;23:1648-54.

25 Bayés de Luna A, Brugada J, Baranchuk A et al. Current electrocardiographic criteria for diagnosis of Brugada pattern: a consensus report. J Electrocardiol 2012;45:433-42.

26 Wilde AA, Antzelevitch C, Borggrefe M et al. Proposed diagnostic criteria for the Brugada syndrome: consensus report. Circulation 2002;106:2514-9.

27 Priori SG, Wilde AA, Horie M et al. HRS/EHRA/APHRS expert consensus statement on the diagnosis and management of patients with inherited primary arrhythmia syndromes: document endorsed by HRS, EHRA, and APHRS in May 2013 and by ACCF, AHA, PACES, and AEPC in June 2013. Heart Rhythm 2013;10:1932-63.

28 Sarkozy A, Sorgente A, Boussy T et al. The value of a family history of sudden death in patients with diagnostic type I Brugada ECG pattern. Eur Heart J 2011;32:2153-60.

29 Miyamoto K, Yokokawa M, Tanaka K et al. Diagnostic and prognostic value of a type 1 Brugada electrocardiogram at higher (third or second) V1 to V2 recording in men with Brugada syndrome. Am J Cardiol 2007;99:53-7.

30 Nagase S, Hiramatsu S, Morita $\mathrm{H}$ et al. Electroanatomical correlation of repolarization abnormalities in Brugada syndrome: detection of type 1 electrocardiogram in the right ventricular outflow tract. J Am Coll Cardiol 2010;56:2143-5.

31 Corrado D, Pellicia A, Antzelevitch C et al. ST segment elevation and sudden cardiac death in the athlete. In: Antzelevitch C, Brugada P, Brugada J, Brugada R (eds), The Brugada Syndrome: from Bench to Bedside. Oxford: Blackwell Science, 2005:119-29.

32 Brugada R, Brugada J, Antzelevitch C et al. Sodium channel blockers identify risk for sudden death in patients with ST-segment elevation and right bundle branch block but structurally normal hearts. Circulation 2000;101:510-5.

33 Priori SG, Napolitano C, Gasparini M et al. Clinical and genetic heterogeneity of right bundle branch block and ST-segment elevation syndrome: a prospective evaluation of 52 families. Circulation 2000;102:2509-15.

34 Brugada P, Brugada R, Brugada J. Should patients with an asymptomatic Brugada electrocardiogram undergo pharmacological and electrophysiological testing? Circulation 2005;112:279-92.

35 Priori SG, Gasparini M, Napolitano C et al. Risk stratification in Brugada Syndrome results of the PRELUDE (PRogrammed ELectrical stimUlation preDictive valuE) registry. J Am Coll Cardiol 2012;59:37-45.

36 Maury P, Hocini M, Haïssaguerre M. Electrical storms in Brugada syndrome: review of pharmacologic and ablative therapeutic options. Indian Pacing Electrophysiol J 2005;5:25-34. 
37 Belhassen B, Glick A, Viskin S. Efficacy of quinidine in high-risk patients with Brugada syndrome. Circulation 2004;110:1731-7.

38 Márquez MF, Bonny A, Hernández-Castillo E et al. Long-term efficacy of low doses of quinidine on malignant arrhythmias in Brugada syndrome with an implantable cardioverterdefibrillator: a case series and literature review. Heart Rhythm 2012;9:1995-2000.

39 Postema PG, Wolpert C, Amin AS et al. Drugs and Brugada syndrome patients: review of the literature, recommendadtions, and an up-to-date website (www.brugadadrugs.org). Heart Rhythm 2009;6:1335-41.
40 Brugada J, Brugada R, Brugada P. Right bundle-branch block and ST-segment elevation in leads V1 through V3: a marker for sudden death in patients without demonstrable structural heart disease. Circulation 1998;97:457-60.

41 Mizusawa Y, Wilde AA. Brugada syndrome. Circ Arrhythm Electrophysiol 2012;5:606-16.

Address for correspondence: Dr AS Sheikh, Royal Glamorgan Hospital, Ynysmaerdy, Llantrisant, Pontyclun CF37 8XR.

Email: drazeemsheikh@hotmail.com

\section{RCP information}

\section{Change of address?}

If you receive Clinical Medicine, please inform us of any changes to your contact details. This helps us to maintain an accurate record of your account and avoids any problem with journal distribution.

Fellows and members should contact the Membership Department: Email: membershipqueries@rcplondon.ac.uk Tel: +44 (0)203075 1362/1467

Institutional subscribers should contact Julie Dalton, Publications Department: Email: julie.dalton@rcplondon.ac.uk Tel: +44 (0)20 30751358

Fax: $+44(0) 2074865425$

\section{Royal College} of Physicians

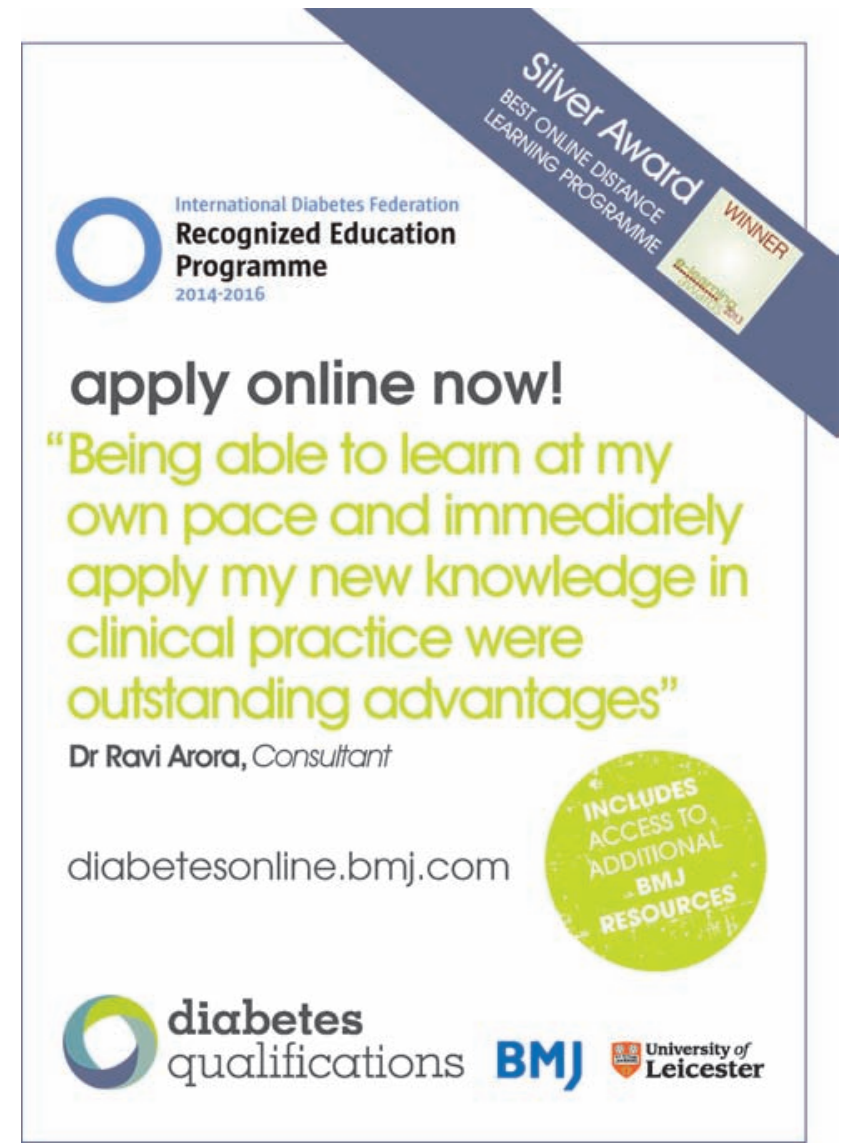

